\title{
Hydrophilic Tetraphenylethene-Based Tetracationic Cyclophanes: NADPH Recognition and Cell Imaging With Fluorescent Switch
}

\author{
Dan $W u^{1 *}$, Zhankui Zhang ${ }^{1}$, Xinyang $\mathrm{Yu}^{2}$, Bing $\mathrm{Bai}^{2}$ and Shaolong $\mathrm{Qi} i^{3 *}$ \\ ${ }^{1}$ College of Materials Science and Engineering, Zhejiang University of Technology, Hangzhou, China, ${ }^{2}$ Key Laboratory of \\ Bioorganic Phosphorus Chemistry and Chemical Biology, Department of Chemistry, Tsinghua University, Beijing, China, ${ }^{3}$ Key \\ Laboratory and Engineering Laboratory of Lymphatic Surgery Jilin Province, China-Japan Union Hospital of Jilin University, \\ Changchun, China
}

OPEN ACCESS

Edited by:

Yong Yao,

Nantong University, China

Reviewed by:

Yue Ding,

Nantong University, China

Zhengwei Mao,

Zhejiang University, China

*Correspondence: Dan Wu

danwu@zjut.edu.cn Shaolong QI

15584187168@163.com

Specialty section:

This article was submitted to

Supramolecular Chemistry,

a section of the journal

Frontiers in Chemistry

Received: 18 November 2021 Accepted: 02 December 2021 Published: 22 December 2021

Citation:

Wu D, Zhang Z, Yu X, Bai B and Qi S (2021) Hydrophilic Tetraphenylethene-

Based Tetracationic Cyclophanes: NADPH Recognition and Cell Imaging

With Fluorescent Switch.

Front. Chem. 9:817720.

doi: 10.3389/fchem.2021.817720
A hydrophilic TPE-based tetracationic cyclophane TPE-cyc was synthesized, which could capture intracellular Nicotinamide adenine dinucleotide phosphate and fuel the antioxidative ability of tumor cells to detoxify reactive oxygen species (ROS). Meanwhile, upon the reduction by cellular GSH, TPE-cyc could light up tumor cells, acting as a GSH-responsive fluorescent switch to image cells with high resolution.

Keywords: tetracationic cyclophanes, tetraphenylethene, NADPH recognition, host-guest complexation, fluorescent switch

\section{INTRODUCTION}

Understanding the significance of molecular recognition in complex biological processes where various nucleic acids, enzymes and nucleotides are involved, has helped chemists to develop intelligent structures with fascinating properties (Meyer et al., 2003; Wu et al., 2017; Wu D et al., 2021). Artificial molecular receptors specific to biomolecules have attracted increasing attentions in recent years owing to their potential applications in medical and biological fields (Jisha et al., 2006; Hariharan et al., 2007; Pluth and Raymond, 2007; Kuruvilla et al., 2008; Ojida et al., 2008; Jisha et al., 2010; Alfonso and Sola, 2020; Escobar and Pablo, 2021). Nicotinamide adenine dinucleotide phosphate (NADPH), a main cellular reductant, plays an important role in maintaining glutathione in its reduced modality (GSH), which eliminates intracellular reactive oxygen species (ROS), thus preventing cells from oxidative damage (Dröge, 2002; Ying, 2008; Celton et al., 2012; Schulze and Harris, 2012; Fernandez-Marcos et al., 2016). Although the probable mechanisms of $\mathrm{NADPH}$-involved physiological processes have been proposed, deeper exploration is still needed due to the complexity and uncertainty of the existing mechanisms. Therefore, a molecular recognition system which can selectively recognize NADPH is urgently needed.

The discovery of crown ethers by Pedersen opened the way for supramolecular chemists to design macrocyclic molecules that act as molecular receptors based on non-covalent interactions or weak coordination (Pedersen, 1967). Since then, chemists have constructed various macrocyclic hosts such as cyclodextrins (Liao et al., 2010; Crini, 2014; Prochowicz et al., 2017; Chen et al., 2021), cucurbit [n]turils (Ong et al., 2002; Jeon et al., 2004; Lagona et al., 2005; Das and Scherman, 2011; Francisco et al., 2019), calix [n] arenes (Ikeda and Shinkai, 1997; Philip kaifer 2002; Sameni et al., 2009; Perret and Coleman, 2011; Li et al., 2020), cyclophanes (Ariga et al., 2005; Si et al., 2014; Strutt et al., 2014; Liu et al., 2017; Sapotta et al., 2019; Neira et al., 2020) and pillararenes (Cao et al., 2014; Li et al., 2014; Ogoshi et al., 2016; Sathiyajith et al., 2017; 


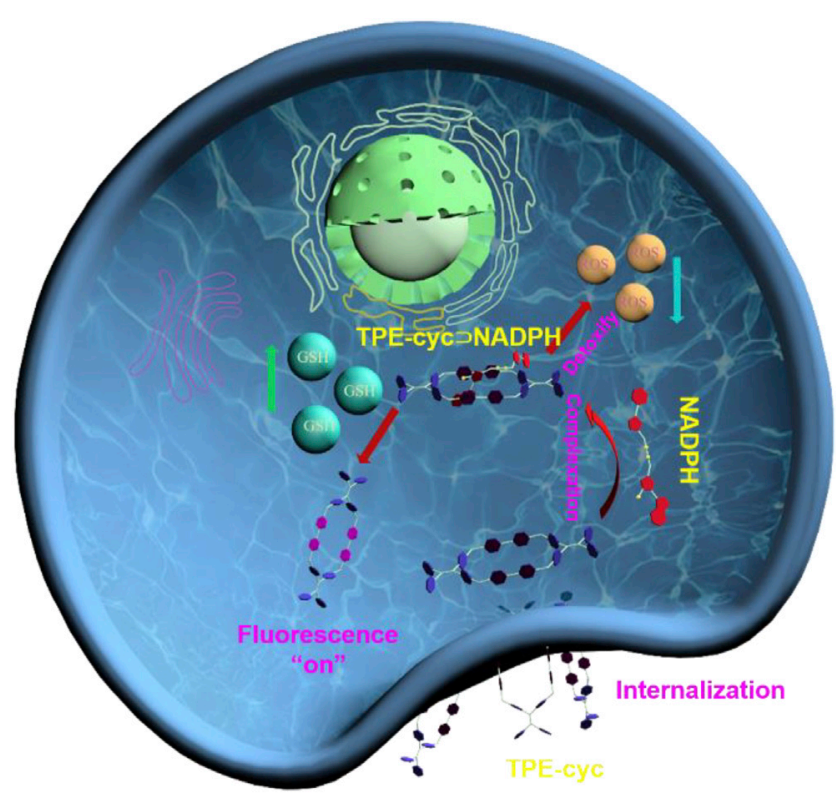

SCHEME 1 | Schematic illustration of the changes of cellular metabolic function regulated by TPE-cyc $\mathrm{NADPH}$.

Guo H et al., 2020; .Cai et al., 2021). The discovery of "blue box" by Stoddart et al. opened the new era of cationic cyclophanes (Gong et al., 2010; Gong et al., 2011; Dale et al., 2016). Cationic cyclophanes are good candidates for molecular recognition because they not only possess multicationic states but also display self-assembly behavior by incorporating $\pi$-electron-rich guests (Trabolsi et al., 2010a; Barnes et al., 2015; Cheng et al., 2015; Chen et al., 2016; Sun et al., 2017). For example, tetracationic cyclophanes which are constructed on the basis of $\pi$-electron-deficient 4,4 'bipyridinium units, can selectively complex with $\pi$-electronrich guests to form 1:1 or 1:2 complexes (Bühner et al., 1988; Philp et al., 1991; Trabolsi et al., 2010b). Recently, tetraphenylethene (TPE) derivatives which are a classic aggregation-induced emission (AIE) luminophores (Zhou et al., 2018; Ding et al., 2021; Wu H et al., 2021), have been utilized as building blocks to construct macrocyclic compounds (Mei et al., 2015). Attributing to the AIE effect and propeller structure, the TPE-based cyclophanes not only display excellent photophysical properties but also possess flexible and diversified cavity structures which can be explored to capture biomolecules (Luo et al., 2012; Zhao et al., 2012; Kwok et al., 2015). Although a number of TPEbased cationic cyclophanes have been utilized for host-guest recognition, the example of biomolecules recognition in aqueous media by hydrophilic TPE-based cationic cyclophanes is rare.

Here, we synthesized a hydrophilic TPE-based tetracationic cyclophane (TPE-cyc), in which TPE and 4.4'-bipyridinium units acted as building blocks. Attributing to the electrostatic interactions and $\pi$ - $\pi$ stacking, TPE-cyc could specifically recognize $\mathrm{NADPH}$ and complex it in a 1:1 manner. After
TPE-cyc being internalized by tumor cells, TPE-cyc could capture cellular NADPH to partially break the equilibrium of $\mathrm{NADPH}$-generating reaction $\left(\mathrm{NADH}+\mathrm{NADP}^{+} \rightarrow \mathrm{NADPH}+\right.$ $\mathrm{NAD}^{+}$) and eventually fuel the NADPH-dependent antioxidative ability to detoxify ROS. Meanwhile, the high concentration of GSH in tumor cells could reduce the 4,4'bipyridinium (MV) units of TPE-cyc into radical cation state and disrupt the photo-induced electron transfer (PET) effect between electron-rich TPE and electron-deficient bipyridinium units, thus recovering the fluorescence of TPE units and lighting up tumor cells (Scheme 1). Hence, TPE-cyc acts as a GSHresponsive fluorescent switch to image cells with high resolution.

\section{MATERIALS AND METHODS}

\section{Materials}

NADPH was purchased from Sigma. TPE-cyc was synthesized according to literature procedures (Cheng et al., 2019). ${ }^{1} \mathrm{H}$ NMR and ${ }^{13} \mathrm{C}$ NMR spectra were recorded on a Bruker Avancelll-400 spectrometry. The 2D NOESY NMR spectra were recorded on a Bruker Avance DMX 600 spectrophotometer with TMS as the internal reference. UV-vis-NIR spectra were taken on a Shimadzu UV-3150 spectrophotometer. The fluorescence experiments were measured on an RF-5301 spectrofluorophotometer (Shimadzu Corporation, Japan). The isothermal titration calorimetry (ITC) experiments were performed on a VP-ITC micro-calorimeter (Microcal, United States). The cell images were taken by a confocal laser scanning microscopy (CLSM, Radiance2100, Bio-Rad) with a $100 \times$ oil immersion lens. Flow cytometry measurements were conducted using a FACSCalibur flow cytometer (BD FACSCalibur). 


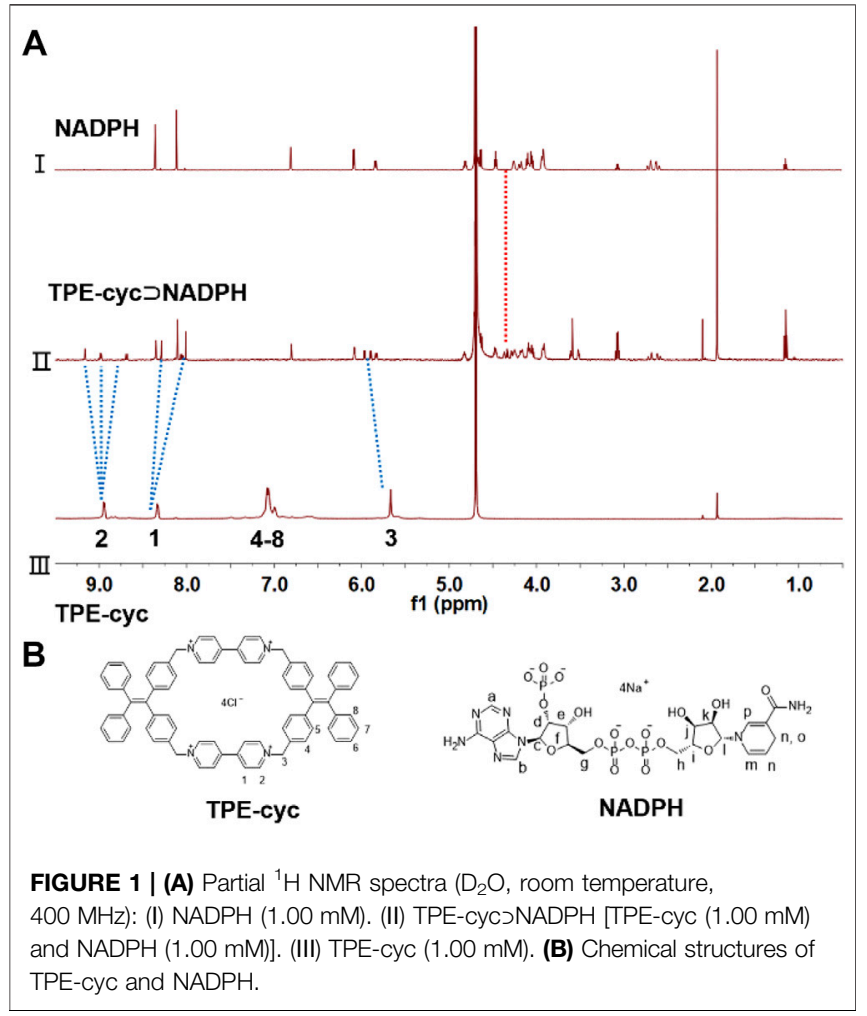

\section{METHODS}

\section{Synthesis of Compound 3}

$37.1 \mathrm{ml} n$-butyllithium $(1.6 \mathrm{M})$ was added into a solution of 1 $(10 \mathrm{~g}, 59.4 \mathrm{mmol})$ in dry THF $(100 \mathrm{ml})$ at $0^{\circ} \mathrm{C}$ under $\mathrm{N}_{2}$ atmosphere. The orange-red solution was stirred for $0.5 \mathrm{~h}$ at $0^{\circ} \mathrm{C}$. Then, $2(6.3 \mathrm{~g}, 29.7 \mathrm{mmol})$ was dissolved in dry THF and dropwise added to the above mixture. The resulting solution was allowed to warm to room temperature and still stirred for $8 \mathrm{~h}$. At last, saturated ammonium chloride solution was added to quench the reaction. The mixture was extracted with DCM three times. The organic phase were combined and dried over anhydrous $\mathrm{Na}_{2} \mathrm{SO}_{4}$. The solvent was removed by rotary evaporation and the acquired crude product was dissolved in toluene with the $4 \AA$ molecular sieve dehydration unit. After addition of catalytic $p$-toluenesulphonic acid $(342 \mathrm{mg}, 1.8 \mathrm{mmol})$, the toluene solution was refluxed for $5 \mathrm{~h}$ and the generated $\mathrm{H}_{2} \mathrm{O}$ was separated. The organic layer was washed with $10 \% \mathrm{NaHCO}_{3}$ aqueous solution and dried over anhydrous $\mathrm{Na}_{2} \mathrm{SO}_{4}$. After removal of toluene, the obtained mixture was purified by column chromatography (silica gel; petroleum ether) to obtain 3 as a white solid $(9.0 \mathrm{~g}, 85 \%)$.

\section{Synthesis of Compound 4}

Under a $\mathrm{N}_{2}$ atmosphere, $3(1.1 \mathrm{~g}, 2.83 \mathrm{mmol})$ was first dissolved in $\mathrm{CCl}_{4}(20 \mathrm{ml})$, then dibenzoyl peroxide $(50 \mathrm{mg}, 0.2 \mathrm{mmol})$ and NBS $(1.5 \mathrm{~g}, 8.49 \mathrm{mmol})$ were added. The mixture was heated to reflux for $12 \mathrm{~h}$. After reaction, the solution was filtered to remove solid impurity and the $\mathrm{CCl}_{4}$ solution was washed with brine three times. The organic phase were collected and dried by anhydrous $\mathrm{Na}_{2} \mathrm{SO}_{4}$. The $\mathrm{CCl}_{4}$ was evaporated and the crude product was purified by a silica gel column chromatography (silica gel; petroleum ether) to obtain 4 as a white solid $(0.9 \mathrm{~g}, 60 \%)$.

\section{Synthesis of Compound 5}

4,4'-bipyridine $(2.0 \mathrm{~g}, 12.8 \mathrm{mmol})$ was dissolved in $\mathrm{CH}_{3} \mathrm{CN}$ $(20 \mathrm{ml})$ and was heated to reflux. Next, compound $4(1.2 \mathrm{mg}$, $2.3 \mathrm{mmol}$ ) was dissolved in $\mathrm{CH}_{3} \mathrm{CN}(5 \mathrm{ml})$ and dropwise added to the bipyridine solution. The resulting mixture was refluxed for

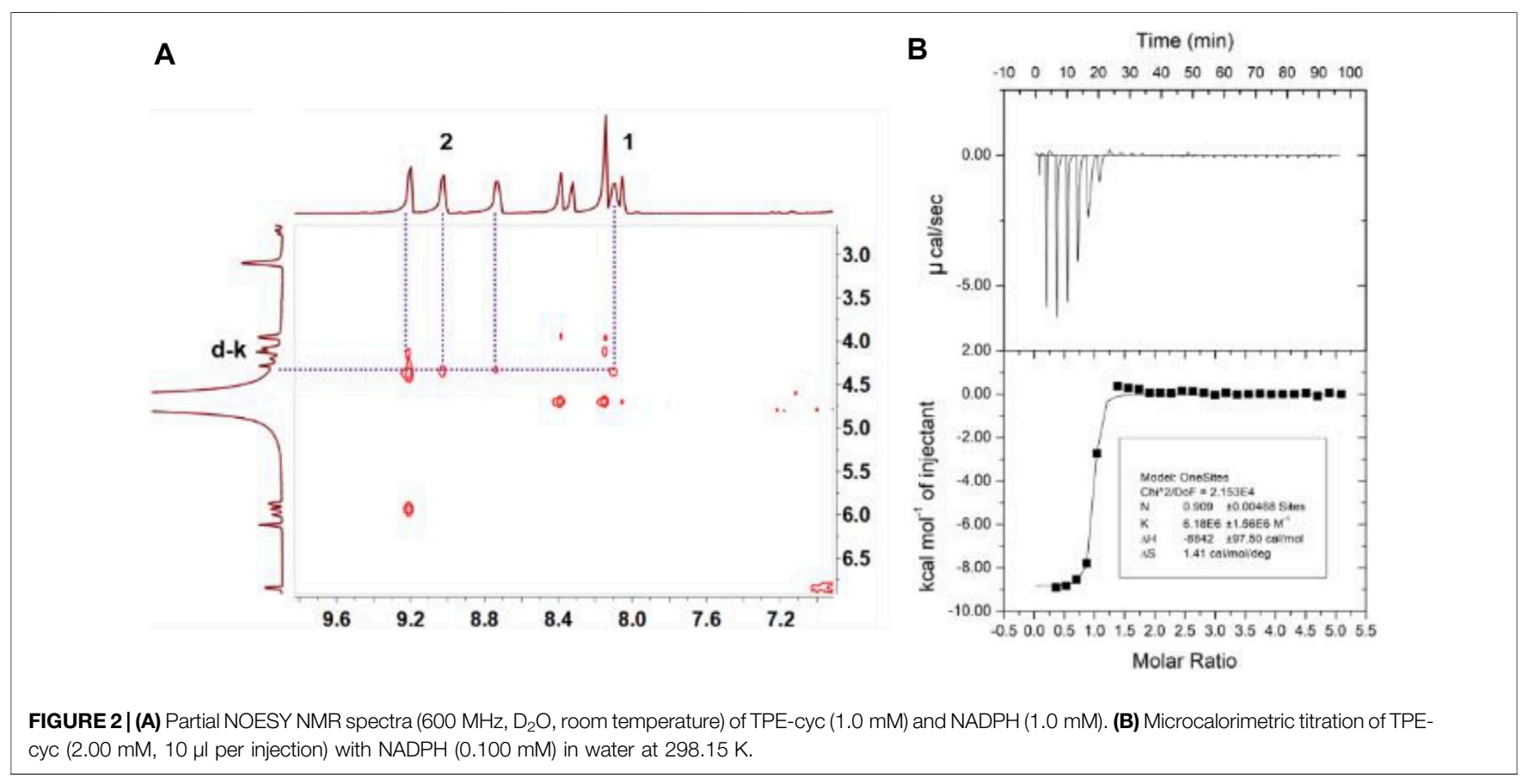



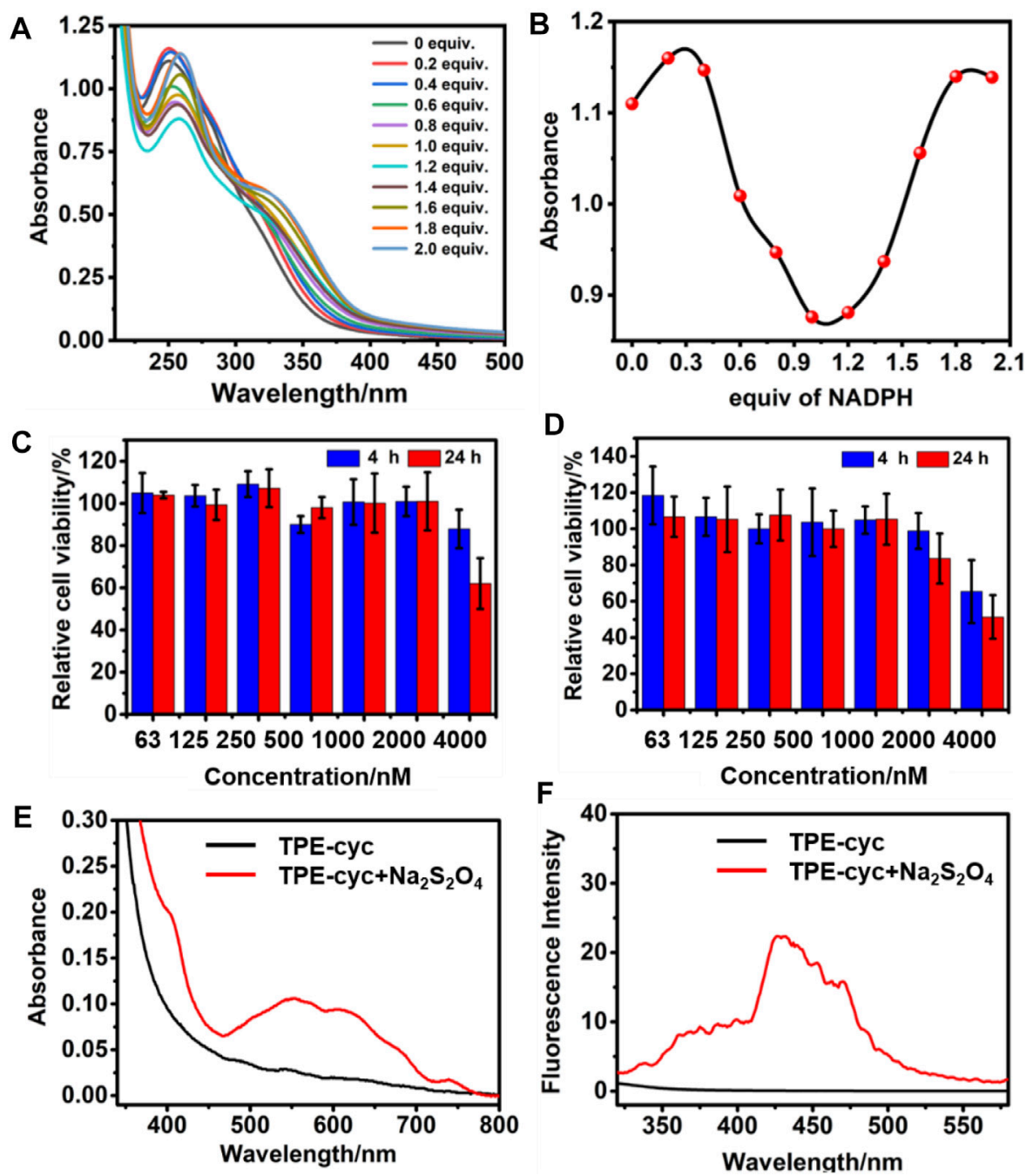

FIGURE 3 | (A) UV/vis spectra of TPE-cyc in the presence of different amounts of NADPH. (B) The plots of UV absorption maximum of TPE-cyc in the presence of different amounts of NADPH. Cytotoxicity of (C) HeLa and (D) U87 cells incubated with different concentrations of TPE-cyc for 4 and $24 \mathrm{~h}$ (E) UV/vis spectra of TPE-cyc with or without $\mathrm{Na}_{2} \mathrm{~S}_{2} \mathrm{O}_{4}$. (F) Fluorescence spectra of TPE-cyc with or without $\mathrm{Na}_{2} \mathrm{~S}_{2} \mathrm{O}_{4}$.

3 days. The formed precipitate was filtered and washed with $\mathrm{CH}_{3} \mathrm{CN}$ three times, and compound 5 was obtained after dry under high vacuum $(1.7 \mathrm{~g}, 90 \%)$.

\section{Synthesis of Compound 6}

Tetrabutylammonium iodide (TBAI, $35 \mathrm{mg}, 0.095 \mathrm{mmol}$ ), 4 (220 mg, $0.42 \mathrm{mmol})$ and $5(400 \mathrm{mg}, 0.42 \mathrm{mmol})$ were dissolved in dry $\mathrm{CH}_{3} \mathrm{CN}(100 \mathrm{ml})$ and was heated at $85^{\circ} \mathrm{C}$ for $72 \mathrm{~h}$. After reaction, the orange product was acquired by centrifuge and dried under high vacuum. After $\mathrm{NH}_{4} \mathrm{PF}_{6}$ anion conversion in water, six was obtained as a pale yellow solid (250 mg, 37\%).

\section{Synthesis of Compound TPE-Cyc}

Tetrabutylammonium chloride (TBACl, $205.66 \mathrm{mg}, 0.74 \mathrm{mmol}$ ) and 6 (100 mg, $0.074 \mathrm{mmol})$ were dissolved in $\mathrm{CH}_{3} \mathrm{CN}$ and stirred overnight. After reaction, the orange terreous product was acquired by centrifuge and washed with $\mathrm{CH}_{3} \mathrm{CN}$ three times. TPE-cyc was obtained after dry in high vacuum (61 mg, 90\%).

\section{RESULTS AND DISCUSSION}

\section{Investigation of Host-Guest Complexation Between TPE-Cyc and NADPH}

TPE-cyc was synthesized via a two-step $\mathrm{S}_{\mathrm{N}} 2$ reaction as shown in Scheme 1. To investigate the host-guest interaction between TPE-cyc and NADPH, ${ }^{1} \mathrm{H}$ NMR spectroscopy was conducted in $\mathrm{D}_{2} \mathrm{O}$. As shown in Figures 1A,B, when an equimolar amount of NADPH and TPE-cyc were mixed in $\mathrm{D} 2 \mathrm{O}$, apparent chemical shift changes of the protons on TPE-cyc were observed. For instance, the signals of protons $\mathrm{H}_{1}, \mathrm{H}_{2}$ and $\mathrm{H}_{3}$ on TPE-cyc were divided into multiple sets of sharp signals with obvious chemical shift changes, which may be induced by the electrostatic 


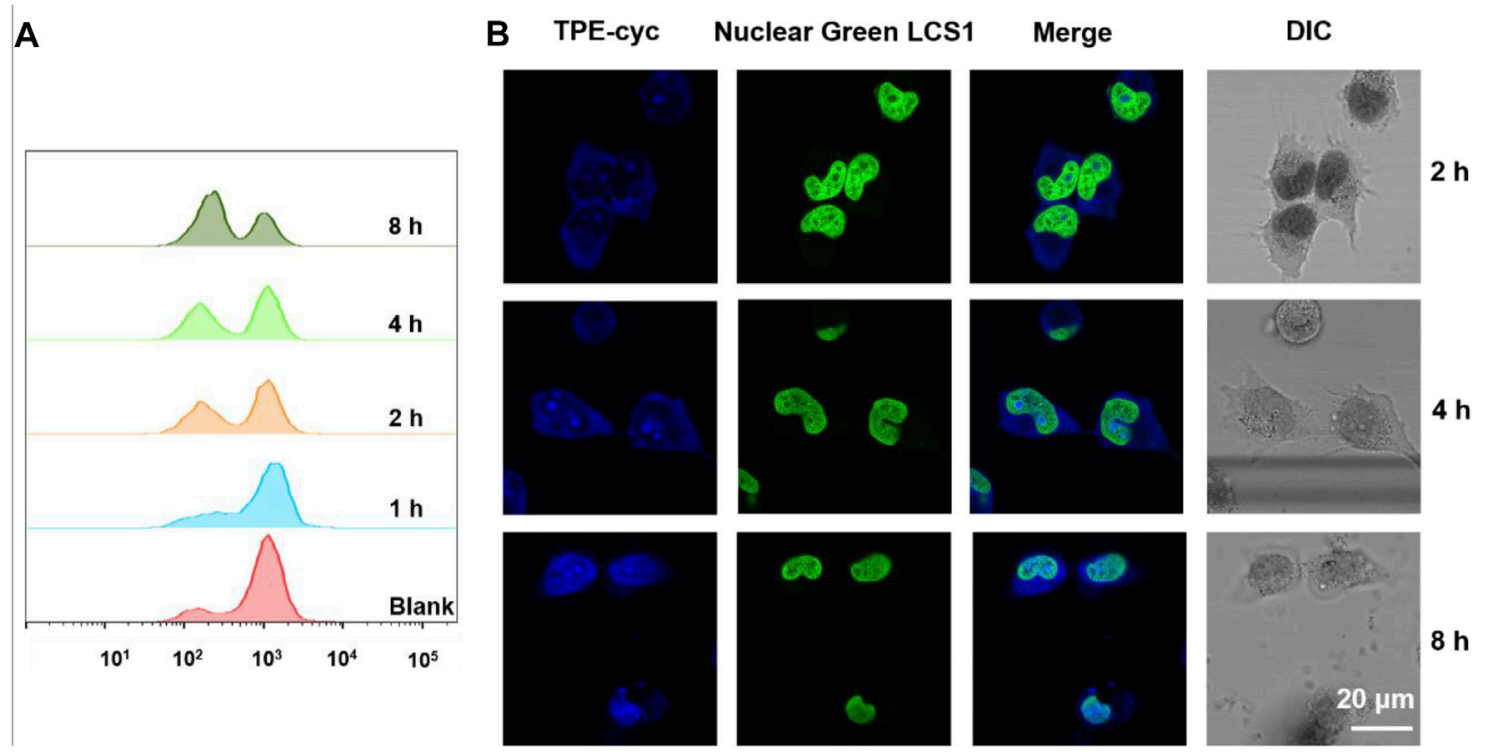

FIGURE 4 | (A) Flow cytometry results of ROS fluorescence signals in HeLa cells incubated with TPE-cyc for different time periods. (B) Confocal images of HeLa cells incubated with TPE-cyc for different time periods (Nuclear Green LCS1 was used to stain nuclei of living HeLa cells).

interaction between the pyridinium unit and tetraphosphate unit of NADPH. Meanwhile, the signals of protons $\mathrm{H}_{4-8}$ disappeared completely after complexation. All these results provided compelling evidence for the host-guest interactions between TPE-cyc and NADPH (Cheng et al., 2019). In addition, the signals of protons on NADPH also displayed obvious peak broadening effect, further indicating the occurrence of host-guest complexation. On the other hand, there were $\mathrm{H}_{1^{-}}$ $\mathrm{H}_{\mathrm{d}-\mathrm{k}}$ and $\mathrm{H}_{2}-\mathrm{H}_{\mathrm{d}-\mathrm{k}}$ inter-correlation between TPE-cyc and $\mathrm{NADPH}$ in nuclear overhauser effect spectroscopy (NOESY) spectrum (Figure 2A), confirming the formation of TPEcyc $\supset$ NADPH.

Isothermal titration calorimetry (ITC) experiment was carried to provide the thermodynamic energy information for the complexation. As shown in Figure $\mathbf{2 B}$, the $K_{\mathrm{a}}$ value of TPEcyc $\supset$ NADPH was calculated to be $(6.18 \pm 1.56) \times 10^{6} \mathrm{M}^{-1}$ and the stoichiometry was $1: 1$. The acquired information of entropy and enthalpy changes $\left(\Delta \mathrm{H}^{\circ}<0 ; \mathrm{T} \Delta \mathrm{S}^{\circ}>0\right)$ from ITC data demonstrated that this supramolecular complexation was promoted by a beneficial entropy-assisted enthalpy change. The driving forces of the molecular recognition were the synergistic effect of hydrophobic interaction, electrostatic interaction and $\pi-\pi$ stacking interaction. Furthermore, there was a fragment peak $m / z=948.3$ [corresponding to (TPEcyc囚NADPH-3Cl-H ${ }^{2+}$ ] in electrospray ionization mass spectrometry (Supplementary Figure S9), which further demonstrated the formation of a 1:1 TPE-cyc $\mathrm{NADPH}$ complex. The UV-vis absorption was also conducted to investigate the complexation between TPE-cyc and NADPH. As shown in Figure 3A, by the continual addition of NADPH into TPE-cyc solution, the maximum absorbance of TPE-cyc at $250 \mathrm{~nm}$ gradually decreased and moved to $258 \mathrm{~nm}$, and the maximum decrease occurred when 1.0 equiv. of NADPH was added (Figure 3B), supporting a 1:1 stoichiometry of TPEcyc $\supset$ NADPH.

\section{Investigation of Cell Viability Regulated by TPE-Cyc}

NADPH is known as a crucial co-enzyme in the event of cellular electron transfer which drives the biosynthesis of amino acids, DNA, phospholipids, fatty acids and steroids. Another important function of NADPH originating from the powerful reducibility of $\mathrm{NADPH}$ is to fuel the activities of various enzymes, such as glutathione peroxidase (GSHPx), catalase and superoxide dismutase, which play an important role in permitting microorganisms to survive in aerobic environment. Hence, breaking the balance of NADPH in living system can induce severe damage for cells, even death. Considering the strong complexing ability of TPE-cyc for NADPH, we investigate the impact of TPE-cyc on biological functions of cells.

The cell viability was firstly assessed by a $3-\left(4^{\prime}, 5^{\prime}-\right.$ dimethylthiazol-2'-yl)-2,5-diphenyl tetrazolium bromide (MTT) assay, wherein U87 and HeLa cells were incubated with different concentrations of TPE-cyc for 4 or $24 \mathrm{~h}$. As shown in Figures 3C,D, cell viability maintained nearly 100\% survival rate in the range of $0.063-1.0 \mu \mathrm{M}$, suggesting this concentration range of TPE-cyc could not disrupt the NADPH balance. However, the survival rate decreased with the further increase of concentration. For example, when the concentration reached $4 \mu \mathrm{M}$, the survival rate fell by half (Figures $3 \mathrm{C}, \mathrm{D}$ ), indicating this concentration of TPE-cyc could capture enough intracellular NADPH and eventually induce cell death. In addition, the cytotoxicity of six was similar to TPE-cyc, suggesting tetracationic macrocyclic structure was the key of cytotoxicity against cells (Supplementary Figure S11). 


\section{Investigation of Antioxidative Ability of Tumor Cells Regulated by TPE-Cyc}

$\mathrm{NADPH}$ has an important ability to keep glutathione in its reduction form GSH, which eliminates ROS and transforms harmful hydrogen peroxide into water under the help of GSHPx (Margis et al., 2008). Therefore, NADPH plays a vital role in resisting cellular oxidative stress. We utilized $2^{\prime}, 7^{\prime}$ dichlorofluorescin diacetate (DCF-DA) as a fluorescence probe to monitor the intracellular ROS level (Li et al., 2018; Ren et al., 2020). DCFH-DA itself does not emit fluorescence, but the intracellular ROS can oxidize the non-emissive DCF-DA into emissive DCF. As shown in Supplementary Figure S12, with the increase of incubation time, the level of ROS in TPE-cyc group decreased, suggesting the antioxidative ability of cells was enhanced. Flow cytometry (FCM) was also applied to quantitatively analyze the level of intracellular ROS. Similar to the result of fluorescence imaging, ROS production significantly decreased with the extension of time (Figure 4A). The reason may be ascribed that the capture of intracellular NADPH by TPEcyc broke the equilibrium of NADPH-involving redox process and triggered the generation of reducing substances which can detoxify ROS.

\section{Investigation of Cell Imaging Ability of TPE-Cyc}

Owing to the PET effect between TPE and bipyridinium units, water-soluble TPE-cyc is a quencher-type host and it has an intense UV absorption but no fluorescence (Hayashida and Kaku, 2013), which severely limits its expansion and application. In the reductive condition, $\mathrm{MV}^{2+}$ can be reduced into $\mathrm{MV}^{++}$and the PET effect between TPE and bipyridinium units is disrupted (Jiao et al., 2019; Guo Q. H et al., 2020; Zhang et al., 2020), which may be used to initiate the fluorescence of TPE-cyc. As shown in Figure 3E, there was a characteristic peak of $\mathrm{MV}^{++}$in the range of $450-750 \mathrm{~nm}$ after addition of $\mathrm{Na}_{2} \mathrm{~S}_{2} \mathrm{O}_{4}$, indicating $\mathrm{MV}^{2+}$ was reduced into $\mathrm{MV}^{++}$ with the help of reducing agent (Lomoth et al., 2002). As expected, there was a new fluorescence emission within the range of $300-550 \mathrm{~nm}$ in the $\mathrm{TPE}-\mathrm{cyc}+\mathrm{Na}_{2} \mathrm{~S}_{2} \mathrm{O}_{4}$ group, suggesting the fluorescence of TPE-cyc was initiated. In tumor cells, the concentration of GSH is high, which can be utilized to light up TPE-cyc. Confocal laser scanning microscopy (CLSM) was utilized to study the internalization behavior of TPE-cyc. As shown in Figure $4 \mathbf{B}$, after $2 \mathrm{~h}$ incubation, apparent blue fluorescence arising from TPE-cyc was observed in the cytoplasm, indicating that TPE-cyc was easily internalized by $\mathrm{HeLa}$ cells. With the incubation time increased to $8 \mathrm{~h}$, the intensity of blue fluorescence significantly increased, suggesting the endocytosis of TPE-cyc occurred in a timedependent mode and intracellular reducing environment ensured continuous luminous of TPE-cyc, which provided a crucial advantage for TPE-cyc to be applied in fluorescence imaging.

\section{CONCLUSION}

In summary, a hydrophilic tetracationic cyclophane was constructed based on TPE and 4,4'-bipyridinium units. Attributing to the large and flat rectangle-like cavity, TPEcyc could specifically recognize NADPH and form a 1:1 host-guest complex. TPE-cyc was not only easily phagocytized by tumor cells but also able to selectively capture cellular NADPH, thus breaking the equilibrium of NADPH-involving redox process and improving the antioxidative ability to eliminate ROS. Meanwhile, the sufficient intracellular reducing environment such as the high concentration of GSH reduced $\mathrm{MV} 2+$ unit of TPE-cyc into $\mathrm{MV}^{++}$to forbid the PET effect between TPE and MV units, realizing the fluorescence recovery of TPE-cyc and eventually fluorescence imaging of tumor cells with high resolution. This current study opens a door for cationic cyclophanes to broaden their biological applications in recognizing biomacromolecules and imaging tumor cells, which has a great potential to diagnose and treat difficult miscellaneous diseases of humans in the future.

\section{DATA AVAILABILITY STATEMENT}

The original contributions presented in the study are included in the article/Supplementary Material, further inquiries can be directed to the corresponding authors.

\section{AUTHOR CONTRIBUTIONS}

DW and SQ conceived and designed the research DW, XY, and BB prepared TPE-cyc and measured the photophysical properties. $\mathrm{ZZ}$ performed the in vitro experiments and analysed the data. DW and SQ co-wrote the paper.

\section{FUNDING}

This work was supported by the Zhejiang Provincial Natural Science Foundation of China (LQ20B040001).

\section{SUPPLEMENTARY MATERIAL}

The Supplementary Material for this article can be found online at: https://www.frontiersin.org/articles/10.3389/fchem.2021.817720/ full\#supplementary-material 


\section{REFERENCES}

Alfonso, I., and Solà, J. (2020). Molecular Recognition of Zwitterions with Artificial Receptors. Chem. Asian J. 15 (7), 986-994. doi:10.1002/ asia.201901789

Ariga, K., Nakanishi, T., Terasaka, Y., Tsuji, H., Sakai, D., and Kikuchi, J. I. (2005). Piezoluminescence at the Air-Water Interface through Dynamic Molecular Recognition Driven by Lateral Pressure Application. Langmuir 21 (3), 976-981. doi:10.1021/la0477845

Barnes, J. C., Dale, E. J., Prokofjevs, A., Narayanan, A., Gibbs-Hall, I. C., Juríček, M., et al. (2015). Semiconducting Single Crystals Comprising Segregated Arrays of Complexes of C60. J. Am. Chem. Soc. 137 (6), 2392-2399. doi:10.1021/ja512959g

Bühner, M., Geuder, W., Gries, W. K., Hünig, S., Koch, M., and Poll, T. (1988). A Novel Type of Cationic Host Molecules Withr-Acceptor Properties. Angew. Chem. Int. Ed. Engl. 27 (11), 1553-1556. doi:10.1002/anie.198815531

Cai, Y., Yan, X., Wang, S., Zhu, Z., Cen, M., Ou, C., et al. (2021). Pillar[5]areneBased 3D Hybrid Supramolecular Polymer for Green Catalysis in Water. Inorg. Chem. 60 (5), 2883-2887. doi:10.1021/acs.inorgchem.0c03645

Cao, Y., Hu, X. Y., Li, Y., Zou, X., Xiong, S., Lin, C., et al. (2014). Multistimuliresponsive Supramolecular Vesicles Based on Water-Soluble Pillar[6]arene and SAINT Complexation for Controllable Drug Release. J. Am. Chem. Soc. 136 (30), 10762-10769. doi:10.1021/ja505344t

Celton, M., Sanchez, I., Goelzer, A., Fromion, V., Camarasa, C., and Dequin, S. (2012). A Comparative Transcriptomic, Fluxomic and Metabolomic Analysis of the Response of Saccharomyces cerevisiae to Increases in NADPH Oxidation. BMC Genomics 13, 317. doi:10.1186/1471-2164-13-317

Chen, L., Lin, Y., Zhang, Z., Yang, R., Bai, X., Liu, Z., et al. (2021). A Novel DualProdrug Carried by Cyclodextrin Inclusion Complex for the Targeting Treatment of colon Cancer. J. Nanobiotechnol. 19, 329. doi:10.1186/s12951021-01064-3

Chen, Q., Sun, J., Li, P., Hod, I., Moghadam, P. Z., Kean, Z. S., et al. (2016). A Redox-Active Bistable Molecular Switch Mounted inside a Metal-Organic Framework. J. Am. Chem. Soc. 138 (43), 14242-14245. doi:10.1021/ jacs.6b09880

Cheng, C., McGonigal, P. R., Schneebeli, S. T., Li, H., Vermeulen, N. A., Ke, C., et al. (2015). An Artificial Molecular Pump. Nat. Nanotech 10 (6), 547-553. doi:10.1038/nnano.2015.96

Cheng, L., Zhang, H., Dong, Y., Zhao, Y., Yu, Y., and Cao, L. (2019). Tetraphenylethene-based Tetracationic Cyclophanes and Their Selective Recognition for Amino Acids and Adenosine Derivatives in Water. Chem. Commun. 55 (16), 2372-2375. doi:10.1039/c9cc00599d

Crini, G. (2014). Review: a History of Cyclodextrins. Chem. Rev. 114 (21), 10940-10975. doi:10.1021/cr500081p

Dale, E. J., Vermeulen, N. A., Juríček, M., Barnes, J. C., Young, R. M., Wasielewski, M. R., et al. (2016). Supramolecular Explorations: Exhibiting the Extent of Extended Cationic Cyclophanes. Acc. Chem. Res. 49 (2), 262-273. doi:10.1021/ acs.accounts.5b00495

Das, D., and Scherman, O. A. (2011). Cucurbituril: At the Interface of Small Molecule Host-Guest Chemistry and Dynamic Aggregates. Isr. J. Chem. 51 (56), 537-550. doi:10.1002/ijch.201100045

Ding, Y., Tong, Z., Jin, L., Ye, B., Zhou, J., Sun, Z., et al. (2021). A NIR Discrete Metallacycle Constructed from Perylene Bisimide and Tetraphenylethylene Fluorophores for Imaging-Guided Cancer Radiochemotherapy. Adv. Mater., 2106388. doi:10.1002/adma.202106388

Dröge, W. (2002). Free Radicals in the Physiological Control of Cell Function. Physiol. Rev. 82 (1), 47-95. doi:10.1152/physrev.00018.2001

Escobar, L., and Ballester, P. (2021). Molecular Recognition in Water Using Macrocyclic Synthetic Receptors. Chem. Rev. 121 (4), 2445-2514. doi:10.1021/acs.chemrev.0c00522

Fernandez-Marcos, P. J., and Nóbrega-Pereira, S. (2016). NADPH: New Oxygen for the ROS Theory of Aging. Oncotarget 7 (32), 50814-50815. doi:10.18632/ oncotarget.10744

Francisco, V., Lino, M., and Ferreira, L. (2019). A Near Infrared Light-Triggerable Modular Formulation for the Delivery of Small Biomolecules. J. Nanobiotechnol. 17, 97. doi:10.1186/s12951-019-0530-y

Gong, H. Y., Rambo, B. M., Karnas, E., Lynch, V. M., Keller, K. M., and Sessler, J. L. (2011). Environmentally Responsive Threading, Dethreading, and Fixation of
Anion-Induced Pseudorotaxanes. I. Am. Chem. Soc. 133 (5), 1526-1533. doi:10.1021/ja109102k

Gong, H. Y., Rambo, B. M., Karnas, E., Lynch, V. M., and Sessler, J. L. (2010). A 'Texas-sized' Molecular Box that Forms an Anion-Induced Supramolecular Necklace. Nat. Chem 2 (5), 406-409. doi:10.1038/nchem.597

Guo, H., Yan, X., Lu, B., Wang, J., Yuan, X., Han, Y., et al. (2020). Pillar[5]arenebased Supramolecular Assemblies with Two-step Sequential Fluorescence Enhancement for Mitochondria-Targeted Cell Imaging. J. Mater. Chem. C 8 (44), 15622-15625. doi:10.1039/D0TC04343E

Guo, Q. H., Zhou, J., Mao, H., Qiu, Y., Nguyen, M. T., Feng, Y., et al. (2020). TetrazineBox: A Structurally Transformative Toolbox. J. Am. Chem. Soc. 142 (11), 5419-5428. doi:10.1021/jacs.0c01114

Hariharan, M., Karunakaran, S. C., and Ramaiah, D. (2007). Selective Recognition of Tryptophan through Inhibition of Intramolecular Charge-Transfer Interactions in an Aqueous Medium. Org. Lett. 9 (3), 417-420. doi:10.1021/ ol062636m

Hayashida, O., and Kaku, Y. (2013). Synthesis of Dabsyl-Appended Cyclophanes and Their Heterodimer Formation with Pyrene-Appended Cyclophanes. J. Org. Chem. 78 (20), 10437-10442. Epub 2013 Sep 30. doi:10.1021/jo4018843

Ikeda, A., and Shinkai, S. (1997). Novel Cavity Design Using Calix[n]arene Skeletons: Toward Molecular Recognition and Metal Binding. Chem. Rev. 97 (5), 1713-1734. doi:10.1021/cr960385x

Jeon, Y. J., Kim, H., Jon, S., Selvapalam, N., Oh, D. H., Seo, I., et al. (2004). Artificial Ion Channel Formed by Cucurbit[n] uril Derivatives with a Carbonyl Group Fringed Portal Reminiscent of the Selectivity Filter of K+ Channels. J. Am. Chem. Soc. 126 (49), 15944-15945. doi:10.1021/ja044748j

Jiao, T., Cai, K., Nelson, J. N., Jiao, Y., Qiu, Y., Wu, G., et al. (2019). Stabilizing the Naphthalenediimide Radical within a Tetracationic Cyclophane. J. Am. Chem. Soc. 141 (42), 16915-16922. doi:10.1021/jacs.9b08926

Jisha, V. S., Arun, K. T., Hariharan, M., and Ramaiah, D. (2006). Site-selective Binding and Dual Mode Recognition of Serum Albumin by a Squaraine Dye. J. Am. Chem. Soc. 128 (18), 6024-6025. doi:10.1021/ja061301x

Jisha, V. S., Arun, K. T., Hariharan, M., and Ramaiah, D. (2010). Site-Selective Interactions: Squaraine Dye-Serum Albumin Complexes with Enhanced Fluorescence and Triplet Yields. J. Phys. Chem. B. 114 (17), 5912-5919. doi:10.1021/jp100369x

Kuruvilla, E., Nandajan, P. C., Schuster, G. B., and Ramaiah, D. (2008). Acridine-Viologen Dyads: Selective Recognition of Single-Strand DNA through Fluorescence Enhancement. Org. Lett. 10 (19), 4295-4298. doi:10.1021/ol801731k

Kwok, R. T. K., Leung, C. W. T., Lam, J. W. Y., and Tang, B. Z. (2015). Biosensing by Luminogens with Aggregation-Induced Emission Characteristics. Chem. Soc. Rev. 44 (13), 4228-4238. doi:10.1039/c4cs00325j

Lagona, J., Mukhopadhyay, P., Chakrabarti, S., and Isaacs, L. (2005). The Cucurbit [n] uril Family. Angew. Chem. Int. Ed. 44 (31), 4844-4870. doi:10.1002/ anie. 200460675

Li, M., Liu, G., Wang, K., Wang, L., Fu, X., Lim, L. Y., et al. (2020). Metal IonResponsive Nanocarrier Derived from Phosphonated Calix[4]arenes for Delivering Dauricine Specifically to Sites of Brain Injury in a Mouse Model of Intracerebral Hemorrhage. J. Nanobiotechnol. 18, 61. doi:10.1186/s12951-020-00616-3

Li, X., Zhao, X., Pardhi, D., Pardhi, D., Wu, Q., Zheng, Y., et al. (2018). Folic Acid Modified Cell Membrane Capsules Encapsulating Doxorubicin and Indocyanine green for Highly Effective Combinational Therapy In Vivo. Acta Biomater. 74, 374-384. doi:10.1016/j.actbio.2018.05.006

Li, Z. Y., Zhang, Y., Zhang, C. W., Chen, L.-J., Wang, C., Tan, H., et al. (2014). Cross-Linked Supramolecular Polymer Gels Constructed from Discrete Multi-Pillar[5] arene Metallacycles and Their Multiple StimuliResponsive Behavior. J. Am. Chem. Soc. 136 (24), 8577-8589. doi:10.1021/ja413047r

Liao, X., Chen, G., Liu, X., Chen, W., Chen, F., and Jiang, M. (2010). Photoresponsive Pseudopolyrotaxane Hydrogels Based on Competition of Host-Guest Interactions. Angew. Chem. Int. Edition 49 (26), 4409-4413. doi:10.1002/anie.201000141

Liu, Z., Nalluri, S. K. M., and Stoddart, J. F. (2017). Surveying Macrocyclic Chemistry: from Flexible crown Ethers to Rigid Cyclophanes. Chem. Soc. Rev. 46 (9), 2459-2478. doi:10.1039/c7cs00185a

Lomoth, R., Häupl, T., Johansson, O., and Hammarström, L. (2002). RedoxSwitchable Direction of Photoinduced Electron Transfer in an $\mathrm{Ru}(\mathrm{bpy}) 3\left(2^{+}\right)$- 
Viologen Dyad. Chem. Eur. J. 8 (1), 102-110. doi:10.1002/15213765(20020104)8:1<102:aid-chem102>3.0.co;2-s

Luo, X., Zhao, W., Shi, J., Li, C., Liu, Z., Bo, Z., et al. (2012). Reversible Switching Emissions of Tetraphenylethene Derivatives Among Multiple Colors with Solvent Vapor, Mechanical, and Thermal Stimuli. J. Phys. Chem. C 116 (41), 21967-21972. doi:10.1021/jp306908u

Margis, R., Dunand, C., Teixeira, F. K., and Margis-Pinheiro, M. (2008). Glutathione Peroxidase Family - an Evolutionary Overview. FEBS J. 275 (15), 3959-3970. doi:10.1111/j.1742-4658.2008.06542.x

Mei, J., Leung, N. L. C., Kwok, R. T. K., Lam, J. W. Y., and Tang, B. Z. (2015). Aggregation-Induced Emission: Together We Shine, United We Soar. Chem. Rev. 115 (21), 11718-11940. doi:10.1021/acs.chemrev.5b00263

Meyer, E. A., Castellano, R. K., and Diederich, F. (2003). Interactions with Aromatic Rings in Chemical and Biological Recognition. Angew. Chem. Int. Ed. 42 (11), 1210-1250. doi:10.1002/anie.200390319

Neira, I., Blanco-Gómez, A., Quintela, J. M., García, M. D., and Peinador, C. (2020). Dissecting the "Blue Box": Self-Assembly Strategies for the Construction of Multipurpose Polycationic Cyclophanes. Acc. Chem. Res. 53 (10), 2336-2346. doi:10.1021/acs.accounts.0c00445

Ogoshi, T., Yamagishi, T. A., and Nakamoto, Y. (2016). Pillar-Shaped Macrocyclic Hosts Pillar[n]arenes: New Key Players for Supramolecular Chemistry. Chem. Rev. 116 (14), 7937-8002. doi:10.1021/ acs.chemrev.5b00765

Ojida, A., Takashima, I., Kohira, T., Nonaka, H., and Hamachi, I. (2008). Turn-on Fluorescence Sensing of Nucleoside Polyphosphates Using a Xanthene-Based $\mathrm{Zn}(\mathrm{II})$ Complex Chemosensor. J. Am. Chem. Soc. 130 (36), 12095-12101. doi:10.1021/ja803262w

Ong, W., Gómez-Kaifer, M., and Kaifer, A. E. (2002). Cucurbit[7]uril: a Very Effective Host for Viologens and Their Cation Radicals. Org. Lett. 4 (10), 1791-1794. doi:10.1021/ol025869w

Pedersen, C. J. (1967). Cyclic Polyethers and Their Complexes with Metal Salts. J. Am. Chem. Soc. 89 (26), 7017-7036. doi:10.1021/ja01002a035

Perret, F., and Coleman, A. W. (2011). Biochemistry of Anionic Calix[n]arenes. Chem. Commun. 47 (26), 7303-7319. doi:10.1039/c1cc11541c

Philip, I. E., and Kaifer, A. E. (2002). Electrochemically Driven Formation of a Molecular Capsule Around the Ferrocenium Ion. J. Am. Chem. Soc. 124 (43), 12678-12679. doi:10.1021/ja028202d

Philp, D., Slawin, A. M. Z., Spencer, N., Stoddart, J. F., and Williams, D. J. (1991). The Complexation of Tetrathiafulvalene by cyclobis(Paraquat-PPhenylene). J. Chem. Soc. Chem. Commun., 1584. doi:10.1039/ C39910001584

Pluth, M. D., and Raymond, K. N. (2007). Reversible Guest Exchange Mechanisms in Supramolecular Host-Guest Assemblies. Chem. Soc. Rev. 36 (2), 161-171. doi:10.1039/b603168b

Prochowicz, D., Kornowicz, A., and Lewiński, J. (2017). Interactions of Native Cyclodextrins with Metal Ions and Inorganic Nanoparticles: Fertile Landscape for Chemistry and Materials Science. Chem. Rev. 117 (22), 13461-13501. doi:10.1021/acs.chemrev.7b00231

Ren, Z., Sun, S., Sun, R., Cui, G., Hong, L., Rao, B., et al. (2020). A MetalPolyphenol-Coordinated Nanomedicine for Synergistic Cascade Cancer Chemotherapy and Chemodynamic Therapy. Adv. Mater. 32 (6), 1906024. doi:10.1002/adma.201906024

Sameni, S., Jeunesse, C., Matt, D., and Harrowfield, J. (2009). Calix[4]arene Daisychains. Chem. Soc. Rev. 38 (7), 2117-2146. doi:10.1039/b900183b

Sapotta, M., Hofmann, A., Bialas, D., and Würthner, F. (2019). A Water-Soluble Perylene Bisimide Cyclophane as a Molecular Probe for the Recognition of Aromatic Alkaloids. Angew. Chem. Int. Ed. 58 (11), 3516-3520. doi:10.1002/ anie. 201813559

Sathiyajith, C., Shaikh, R. R., Han, Q., Zhang, Y., Meguellati, K., and Yang, Y. W. (2017). Biological and Related Applications of Pillar[n]arenes. Chem. Commun. 53 (4), 677-696. doi:10.1039/c6cc08967d
Schulze, A., and Harris, A. L. (2012). How Cancer Metabolism Is Tuned for Proliferation and Vulnerable to Disruption. Nature 491 (7424), 364-373. doi:10.1038/nature11706

Si, W., Li, Z. T., and Hou, J. L. (2014). Voltage-driven Reversible Insertion into and Leaving from a Lipid Bilayer: Tuning Transmembrane Transport of Artificial Channels. Angew. Chem. Int. Ed. 53 (18), 4578-4581. doi:10.1002/anie.201311249

Strutt, N. L., Zhang, H., Schneebeli, S. T., and Stoddart, J. F. (2014). Functionalizing Pillar[n]arenes. Acc. Chem. Res. 47 (8), 2631-2642. doi:10.1021/ar500177d

Sun, J., Liu, Z., Liu, W. G., Wu, Y., Wang, Y., Barnes, J. C., et al. (2017). MechanicalBond-Protected, Air-Stable Radicals. J. Am. Chem. Soc. 139 (36), 12704-12709. doi:10.1021/jacs.7b06857

Trabolsi, A., Fahrenbach, A. C., Dey, S. K., Share, A. I., Friedman, D. C., Basu, S., et al. (2010a). A Tristable [2]pseudo[2] rotaxane. Chem. Commun. 46 (6), 871-873. doi:10.1039/b918321c

Trabolsi, A., Khashab, N., Fahrenbach, A. C., Friedman, D. C., Colvin, M. T., Cotí, K. K., et al. (2010b). Radically Enhanced Molecular Recognition. Nat. Chem 2 (1), 42-49. doi:10.1038/nchem.479

Wu, D., Li, Y., Yang, J., Shen, J., Zhou, J., Hu, Q., et al. (2017). Supramolecular Nanomedicine Constructed from Cucurbit[8]uril-Based Amphiphilic Brush Copolymer for Cancer Therapy. ACS Appl. Mater. Inter. 9 (51), 44392-44401. doi:10.1021/acsami.7b16734

Wu, D., Wang, S., Yu, G., and Chen, X. (2021). Cell Death Mediated by the Pyroptosis Pathway with the Aid of Nanotechnology: Prospects for Cancer Therapy. Angew. Chem. Int. Ed. 60 (15), 8018-8034. doi:10.1002/anie.202010281

Wu, H., Chen, Z., Qi, S., Bai, B., Ye, J., Wu, D., et al. (2021). Evaluation of the Stability of Cucurbit[8]uril-Based Ternary Host-guest Complexation in Physiological Environment and the Fabrication of a Supramolecular Theranostic Nanomedicine. J. Nanobiotechnol. 19, 330. doi:10.1186/s12951-021-01076-z

Ying, W. (2008). NAD $/ \mathrm{NADH}$ and $\mathrm{NADP}^{+} / \mathrm{NADPH}$ in Cellular Functions and Cell Death: Regulation and Biological Consequences. Antioxid. Redox Signaling 10 (2), 179-206. doi:10.1089/ars.2007.1672

Zhang, Y., Chen, Q., Wang, Y., Zheng, X., Wang, H., Cao, F., et al. (2020). A Bistable [2]catenane Switched by Hetero-Radical Pairing Interactions. Chem. Commun. 56 (79), 11887-11890. doi:10.1039/d0cc02012e

Zhao, N., Yang, Z., Lam, J. W. Y., Sung, H. H. Y., Xie, N., Chen, S., et al. (2012). Benzothiazolium-functionalized Tetraphenylethene: an AIE Luminogen with Tunable Solid-State Emission. Chem. Commun. 48 (69), 8637-8639. doi: $10.1039 / \mathrm{c} 2 \mathrm{cc} 33780 \mathrm{k}$

Zhou, S., Zhao, H., Feng, R., Ding, L., Li, Z., Deng, C., et al. (2018). Application of Amphiphilic Fluorophore-Derived Nanoparticles to Provide Contrast to Human Embryonic Stem Cells without Affecting Their Pluripotency and to Monitor Their Differentiation into Neuron-like Cells. Acta Biomater. 78, 274-284. doi:10.1016/j.actbio.2018.07.051

Conflict of Interest: The authors declare that the research was conducted in the absence of any commercial or financial relationships that could be construed as a potential conflict of interest.

Publisher's Note: All claims expressed in this article are solely those of the authors and do not necessarily represent those of their affiliated organizations, or those of the publisher, the editors and the reviewers. Any product that may be evaluated in this article, or claim that may be made by its manufacturer, is not guaranteed or endorsed by the publisher.

Copyright $\odot 2021 \mathrm{Wu}$, Zhang, Yu, Bai and Qi. This is an open-access article distributed under the terms of the Creative Commons Attribution License (CC BY). The use, distribution or reproduction in other forums is permitted, provided the original author(s) and the copyright owner(s) are credited and that the original publication in this journal is cited, in accordance with accepted academic practice. No use, distribution or reproduction is permitted which does not comply with these terms. 